\title{
Corrosion Resistance of AZ91 Mg Alloy Modified by High-Current Pulsed Electron Beam
}

\author{
Peng-Peng $\mathrm{Wu}^{1} \cdot$ Kun-Kun Deng ${ }^{1} \cdot \mathrm{Kai}^{-B o} \mathrm{Nie}^{1} \cdot$ Zhong-Zhong Zhang $^{1}$
}

Received: 4 May 2018/Revised: 27 June 2018/Published online: 30 August 2018

(C) The Chinese Society for Metals and Springer-Verlag GmbH Germany, part of Springer Nature 2018

\begin{abstract}
The high-current pulsed electron beam (HCPEB) treatment with current density $6 \mathrm{~J} / \mathrm{cm}^{2}$ was applied on AZ91 Mg alloy to improve its corrosion resistance. Results showed that the net-like $\mathrm{Mg}_{17} \mathrm{Al}_{12}$ disappeared on the surface of $\mathrm{AZ91} \mathrm{Mg}$ alloy after irradiation by HCPEB, which was instead of supersaturated Al element on the surface. Nevertheless, the application of HCPEB also led to the formation of crater-like and groove-like structures as well as micro-cracks on the surface of AZ91 Mg alloy. After HCPEB treatment by 3, 5 and 10 pulses, the AZ91 Mg alloy exhibited better corrosion resistance. However, the increasing amount of micro-cracks reduced the anti-corrosive properties of AZ91 Mg alloy as the pulse increased to 20 and 30 .
\end{abstract}

Keywords High-current pulsed electron beam (HCPEB) · Corrosion resistance $\cdot$ Electrochemical impedance spectroscopy (EIS) $\cdot$ AZ91 Mg alloy · Microstructure

\section{Introduction}

Magnesium and its alloys have been considered the promising candidate structure materials due to their low density and high specific strength [1-3]. For past decades, they have received great interests as degradable biomaterials among researches because of their biocompatibilities and low elastic modulus which are close to nature bones [4]. However, the poor corrosion resistance may delay the healing of the tissue $[5,6]$. There are two ways to improve its corrosion resistance: Firstly, alloying design and plastic deformation [7-10] as well as heat treatment [11] are applied to weaken the galvanic corrosion and promote the formation of a compact and stable surface or passive film on the surface of Mg alloys. Secondly, surface modification like chemical conversion treatment [12, 13], sol-gel method [14, 15] and micro-arc oxidation [16] was widely

Available online at http://link.springer.com/journal/40195

Kun-Kun Deng

jamsdk@163.com; dengkunkun@tyut.edu.cn

1 Shanxi Key Laboratory of Advanced Magnesium-Based Materials, College of Materials Science and Engineering, Taiyuan University of Technology, Taiyuan 030024, China used to improve the anti-corrosive performance of $\mathrm{Mg}$ and its alloys.

As a new surface modification technology of materials, high-current pulsed electron beam (HCPEB) has been applied on metals like steels [17, 18], Ti alloys [19] and $\mathrm{Mg}$ alloys [20-22] due to its high efficiency, simple operability, reliability and comprehensive performance. The electron beam with high energy density allows achieving heating rates of the target of up to $\sim 10^{9} \mathrm{~K} / \mathrm{s}$ within a short pulse of microseconds $(\sim 4 \mu \mathrm{s})$. After that, self-quenching will happen due to high temperature gradient within material, and the cooling rates can be $\sim 10^{8} \mathrm{~K} / \mathrm{s}$ [23]. The extremely high heating and cooling rates result in complex physical processes including (1) improving dislocation density, (2) occurrence of the non-equilibrium structures such as nanocrystals, amorphous phase and supersaturated solid solution and (3) thermal stress.

In fact, the HCPEB had been used to modify the microstructure and wear resistance of AZ91 alloy [20-22]. Based on the investigation of $\mathrm{Li}$ et al. [22], the homogenous nanostructures could be obtained on the surface of AZ91 Mg alloy by HCPEB treatment. Nevertheless, the formation of supersaturated $\mathrm{Al}$ element and deformation layer induced by stress waves on the surface would also improve the AZ91 alloy's surficial wear resistance [20]. Moreover, Hao [21] reported that corrosion resistance of 
AZ91 Mg alloy can be improved by supplying of 15 pulses of HCPEB modification. However, corrosion mechanism of AZ91 Mg alloys processed by HCPEB surficial modification with different pulses is lacking in the literature. Nevertheless, the relationship between microstructure and corrosion properties of HCPEB-treated AZ91 Mg alloy is still unclear. As a consequence, the microstructure and anti-corrosive performance of AZ91 Mg alloy processed by HCPEB surficial modification with different pulses will be studied.

\section{Experimental}

The material used in present work was a commercial AZ91 Mg alloy, and the composition is: Al $9.3 \mathrm{wt} \%, \mathrm{Zn}$ $0.7 \mathrm{wt} \%$, Mn $0.23 \mathrm{wt} \%$, other alloy elements $<0.2 \mathrm{wt} \%$ and $\mathrm{Mg}$ balance. The samples were cut into cylinder (10 $\mathrm{mm}$ in diameter, $3 \mathrm{~mm}$ in thickness) with an irradiation area of $0.785 \mathrm{~cm}^{2}$ and then ground to $\mathrm{P} 4000$ grit with $\mathrm{SiC}$ waterproof abrasive papers before HCPEB treatment.

The HCPEB surface modification (RITM-2 M type) was performed as following experimental parameters: accelerating voltage $\sim 40 \mathrm{kV}$, pulse duration $2.5 \mu \mathrm{s}$, energy density $6 \mathrm{~J} / \mathrm{cm}^{2}$, pulse number $3,5,10,20$ and 30 .

Microstructure of the samples before and after HCPEB irradiation was observed by optical microscopy (OM, 4XC) and a scanning electron microscope (SEM, MIRA3 XMU/XMH) equipped with an energy-dispersive $\mathrm{X}$-ray spectroscopy analysis system (EDS). Phase change before and after HCPEB treatment was detected by X-ray diffraction (XRD, DX-2700) measurement. The scanning range $(2 \theta)$ was from $20^{\circ}$ to $80^{\circ}$ with step length of $0.03^{\circ}$.

For electrochemical tests (CHI 660E), the samples were immersed into the simulated body fluid (SBF) solution at $37 \pm 1{ }^{\circ} \mathrm{C}$ for $30 \mathrm{~min}$ to obtain a steady opencircuit potential (OCP) before electrochemical impedance spectroscopy (EIS) test and potentiodynamic polarization (PDP) test. The electrochemical corrosion system consisted of the sample, a saturated calomel electrode (SCE), a Pt plate with dimensions of $10 \mathrm{~mm} \times 10 \mathrm{~mm} \times 0.5$ $\mathrm{mm}$ as the working, reference and counter electrodes, respectively. The frequency range of EIS test was from $10^{5}$ to $10^{-2} \mathrm{~Hz}$ with an amplitude of $5 \mathrm{mV}$ at OCP. PDP test was performed with a scan rate of $5 \mathrm{mV} \mathrm{s}^{-1}$ over a potential range from $-1.75 \mathrm{~V}$ versus $\mathrm{SCE}$ to $-0.75 \mathrm{~V}$ versus SCE. Due to the abnormal anodic behavior (i.e negative difference effect) of $\mathrm{Mg}$ and its alloys [24, 25], the corrosion current density $\left(i_{\text {corr }}\right)$ was obtained by using cathodic branch. The $i_{\text {corr }}$ obtained from polarization curves was used to calculate the corrosion rate by the following equation [26]:

$C_{\mathrm{R}}=22.85 i_{\text {corr }}$,

where $C_{\mathrm{R}}$ is corrosion rate in $\mathrm{mm} / \mathrm{year}$ and $i_{\text {corr }}$ is the corrosion current density in $\mathrm{mA} / \mathrm{cm}^{2}$. Three tests were conducted for each group, and the average values were obtained.

\section{Results}

Figure 1a shows the typical OM images of untreated AZ91 Mg alloy. It can be clearly found that the continuous net-like $\mathrm{Mg}_{17} \mathrm{Al}_{12}$ phase distributes along grain boundaries. After 3 pulses of HCPEB treatment, the surface becomes rough (Fig. 1b). Dense globular bulges and groove-like structures as well as crater-like defects can be found. According to the investigation of Hao et al. [21], $\mathrm{Mg}_{17} \mathrm{Al}_{12}$ phase could provide the favorable positions of these defects. With increasing pulses to 5 , the crater-like defects are obvious and the globular bulges almost disappear (Fig. 1c). Meantime, groove-like structures still exist on the surface. Density of crater-like and groove-like structures decreases as the pulses further increase. Meanwhile, the width of groove-like structure becomes coarse with the increasing pulses (Fig. 1d-f).

The SEM micrographs of treated samples are shown in Fig. 2. The surface presents typical characteristic: microcracks (indicated by dashed arrows) caused by the thermal stress produced in surface layer during the rapid solidification and quenching processes of HCPEB treatment [21] and crater-like defects (indicated by solid arrows) as a result of eruption of $\mathrm{Mg}_{17} \mathrm{Al}_{12}$ phase. Density of microcracks increases as the pulses increase. Meanwhile, some white and gray particles appear. EDS results (Table 1) show that these particles contain much more Al element than that in the matrix. According to the XRD results in Fig. 3a, these particles can be confirmed as $\mathrm{Mg}_{17} \mathrm{Al}_{12}$ phase. Thus, it can be conducted that $\mathrm{Mg}_{17} \mathrm{Al}_{12}$ phase precipitates during the modification process. Besides, Fig. 2a-c shows that the amount of precipitated $\mathrm{Mg}_{17} \mathrm{Al}_{12}$ phase increases, and the size of which increases as the pulses increased to 10 . However, lots of small pits appear and the amount of $\mathrm{Mg}_{17} \mathrm{Al}_{12}$ phase decreases on the surface of AZ91 alloy as the pulses are further increased to 30 .

In fact, the temperature on the surface of alloy rises sharply during HCPEB irradiation process [17-23]. Local melting of partial $\mathrm{Mg}_{17} \mathrm{Al}_{12}$ phase starts at the subsurface layer, which induces the quasi-static thermal stress [21]. Given to the quasi-static thermal stress and metal liquid expanding, the melted $\mathrm{Mg}_{17} \mathrm{Al}_{12}$ phase droplets erupt. After that, the melted metal solidifies rapidly due to the 

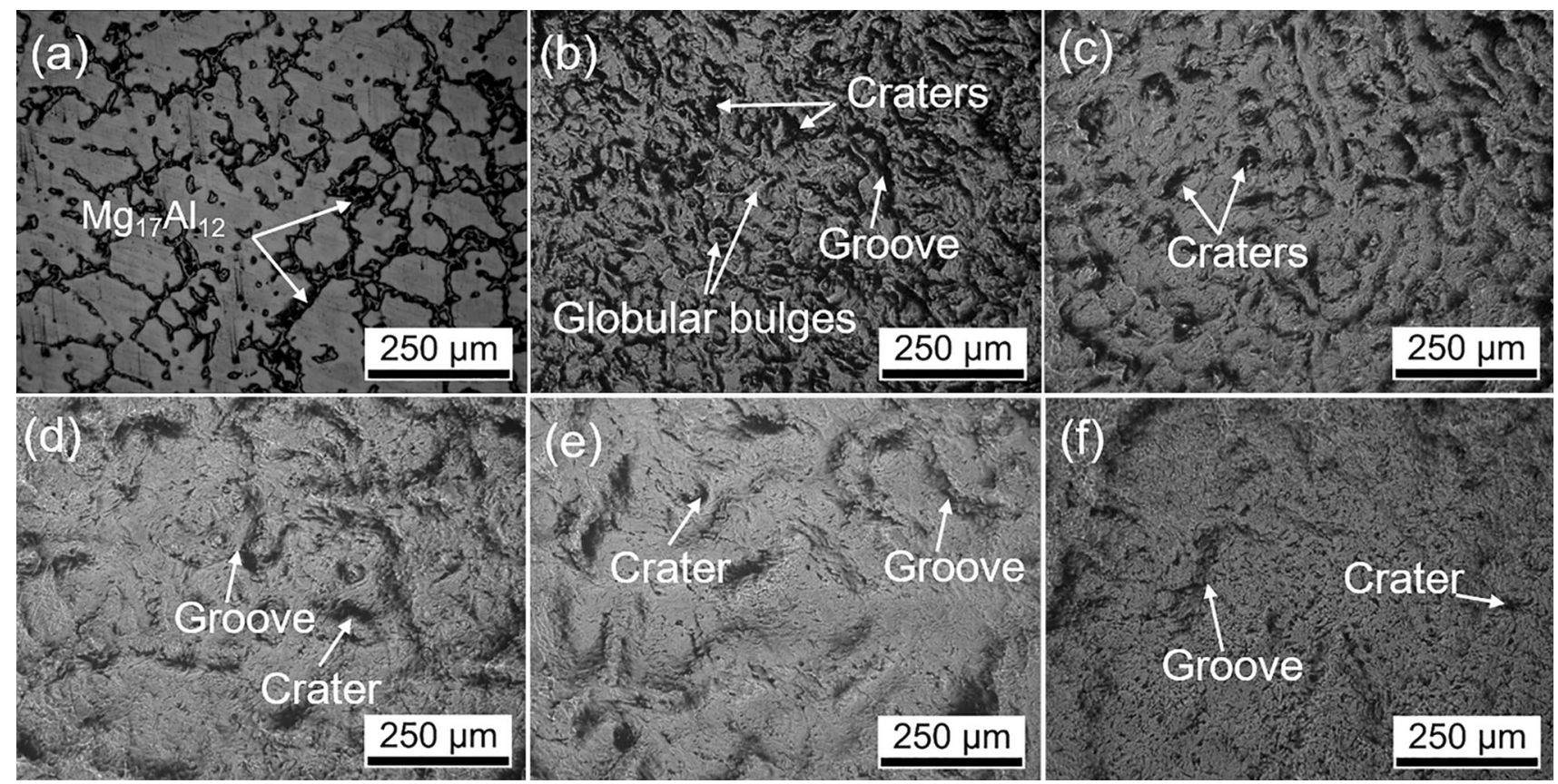

Fig. 1 OM images of AZ91 Mg alloy: a untreated and treated by HCPEB at the pulse of b 3, c 5, d 10, e 20, f 30
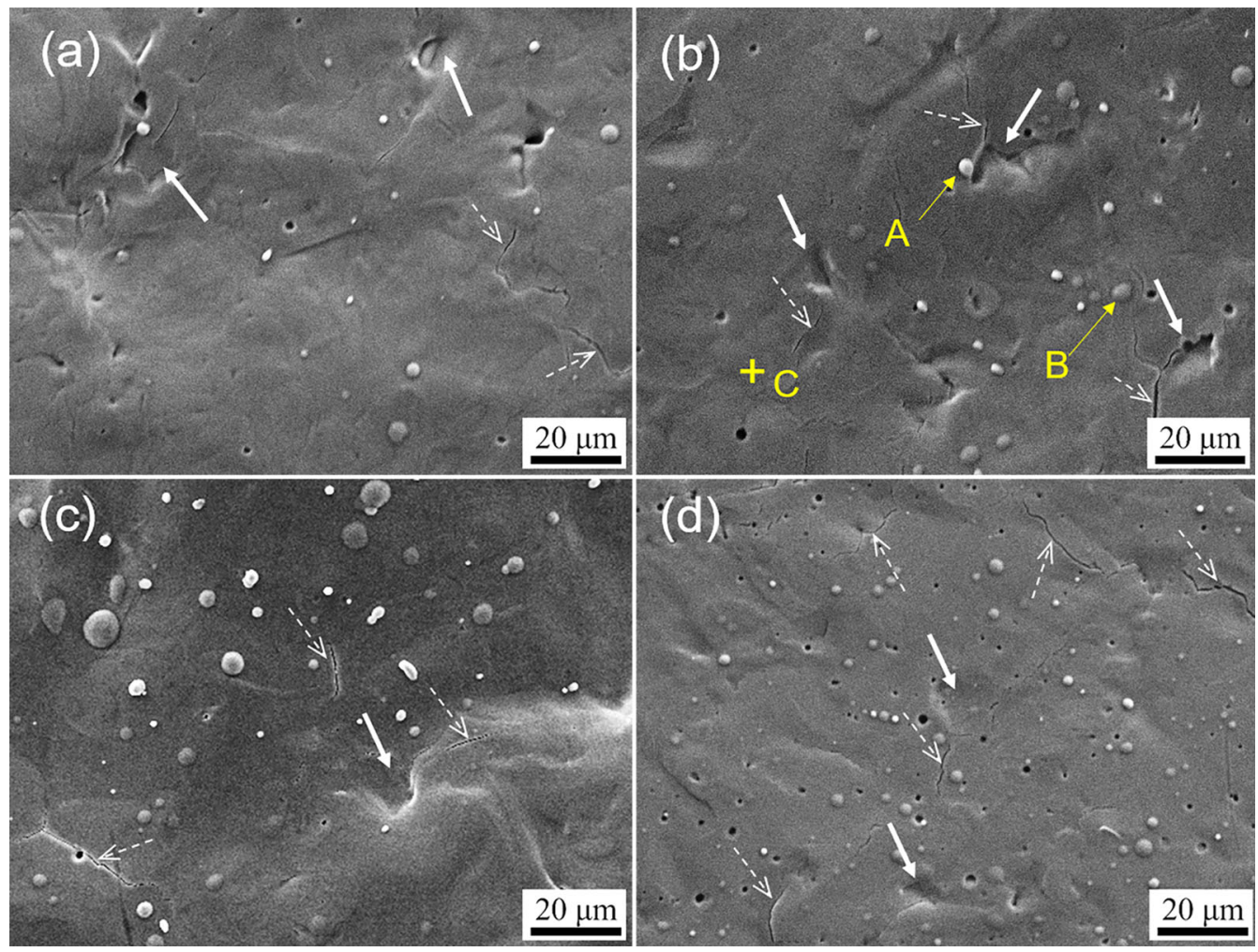

Fig. 2 SEM micrographs of AZ91 Mg alloy treated by HCPEB at the pulse of a 3, b 5, c 10, d 30

extreme difference in temperature between top surface and matrix. As a result, the crater- and groove-like structures as well as micro-cracks are formed on the surface. The impact force from eruption of melted $\mathrm{Mg}_{17} \mathrm{Al}_{12}$ leads to the previous plastic deformation of grains around $\mathrm{Mg}_{17} \mathrm{Al}_{12}$ phase, and then, globular bulges are observed. As the pulses increased to 5 , more $\mathrm{Mg}_{17} \mathrm{Al}_{12}$ phase melted and erupted. This results in appearance of more craters in 
Table 1 EDS results of points in Fig. $2 b$

\begin{tabular}{llll}
\hline Points & \multicolumn{3}{l}{ Elements (at.\%) } \\
\cline { 2 - 4 } & $\mathrm{Mg}$ & $\mathrm{Al}$ & $\mathrm{Zn}$ \\
\hline$A$ & 61.1 & 38.5 & 0.4 \\
$B$ & 76.3 & 23.1 & 0.6 \\
$C$ & 84.3 & 15.0 & 0.7 \\
\hline
\end{tabular}

Figs. 1c and 2b. As the pulses further increase to 10, $\mathrm{Mg}_{17} \mathrm{Al}_{12}$ phase melted completely and the temperature gradient between top surface and matrix reduces for longer duration of heat transmission. The solidification rate decreases, and the modified surface becomes flatten (Fig. 1b-d). This also results in more precipitation of $\mathrm{Mg}_{17} \mathrm{Al}_{12}$ phase. With the further increase of pulses, the temperature can exceed the boiling point of matrix and $\mathrm{Mg}_{17} \mathrm{Al}_{12}$ phase. After evaporation of precipitated $\mathrm{Mg}_{17}$ $\mathrm{Al}_{12}$ phase, the small pits are formed, as shown in Fig. $2 \mathrm{~d}$. Moreover, the temperature gradient between top surface and matrix further reduces, and the surface becomes more flatten.

Figure 4 shows the EDS-layered map of untreated AZ91 Mg alloy and AZ91 modified by HCPEB at 5 pulses. It can be clearly found that the $\mathrm{Al}$ element distributes mainly at $\mathrm{Mg}_{17} \mathrm{Al}_{12}$ phase in the $\mathrm{AZ91} \mathrm{Mg}$ alloy (Fig. 4b). Nevertheless, the Al element distributes uniformly in the matrix after HCPEB treatment by 5 pulses, as shown in Fig. 4d. Furthermore, the matrix after treatment contains more Al than that without treatment according to the EDS results. The $\mathrm{Al}$ content at the surface of AZ91 Mg alloy after HCPEB treatment is summarized in Fig. 5. It could be noted that all of the HCPEB-treated alloys show higher Al content than that without HCPEB treatment. Such phenomenon can be attributed to the superfast solidification process of $\mathrm{HCPEB}$ treatments. Actually, the $\mathrm{Al}$ atoms in $\mathrm{Mg}_{17} \mathrm{Al}_{12}$ phase can solve into $\boldsymbol{\alpha}-\mathrm{Mg}$ matrix during the heating process of HCPEB treatment [21]. However, not all those $\mathrm{Al}$ atoms can precipitate due to the rapid cooling rate. As a result, the surface of AZ91 alloy contains more Al element as compared with that without HCPEB treatment. Such solidification also causes the phenomenon that the $\alpha$ $\mathrm{Mg}$ (0002) diffraction peak shifted to the right [21] (Fig. 3b). The alloy treated by 5 pulses shows the highest $\mathrm{Al}$ contents than other alloys treated by HCPEB. But the $\mathrm{Al}$ content on the surface of AZ91 alloy decreases when the pulses are more than 10 . This is caused by the precipitation of $\mathrm{Mg}_{17} \mathrm{Al}_{12}$ phase, which has already been discussed above.

Figure 6 shows the OM micrographs of cross-sectional morphology irradiated for 5 pulses and 30 pulses. After HCPEB treatment by 5 pulses, the interface between substrate and melt layer can be distinguished clearly. The melt layer is uneven, and the thickness is about 5-10 $\mu \mathrm{m}$. The eruption-like sign of $\mathrm{Mg}_{17} \mathrm{Al}_{12}$ phase can be recognized (indicated by dashed arrow) in Fig. 6a. After HCPEB treatment by 30 pulses, the melt layer is uniform and the thickness is about $10-12 \mu \mathrm{m}$, whereas the alloy shows multiple melt layers and interface. This is caused by the repeated melt and solidification. During the modification process, the melting metal solidifies rapidly due to the extreme cooling rate. The solidified metal can be heated again and then melt during the later irradiation. As a result, the surface shows multiple layers and interface.

Figure 7 shows the PDP curves, and the details of corrosion parameters obtained from PDP curves are listed in Table 2. Compared with AZ91 Mg alloy, the $E_{\text {corr }}$ values of those alloys modified by HCPEB treatment shift to noble direction by $48 \mathrm{mV}, 81 \mathrm{mV}, 203 \mathrm{mV}, 282 \mathrm{mV}$ and $198 \mathrm{mV}$ after HCPEB treatment by 3, 5, 10, 20 and 30 pulses, respectively, indicating the corrosion tendency of AZ91 Mg alloy can be suppressed by HCPEB treatment, while the $i_{\text {corr }}$ values decrease as the pulses of HCPEB increase to 5 and then increase accompanied by further increase of pulse. The reduction in $i_{\text {corr }}$ values is more
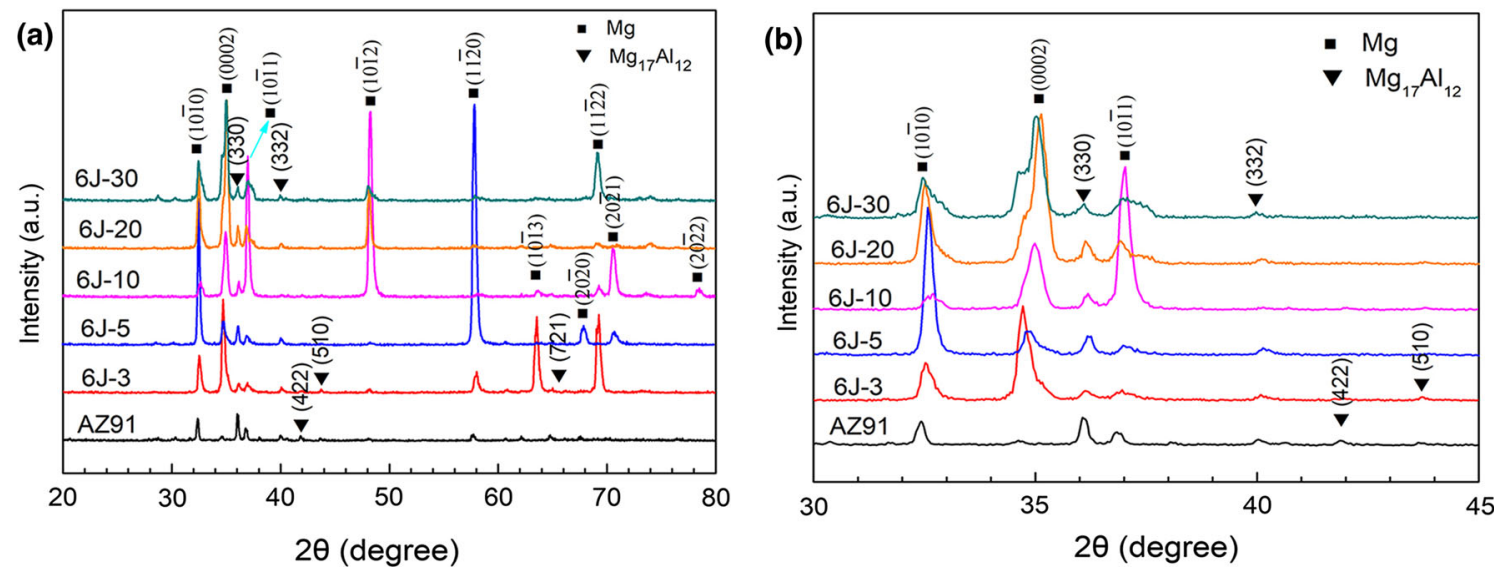

Fig. $3 \mathrm{XRD}$ patterns of the samples: a $2 \theta$ range from $20^{\circ}$ to $80^{\circ}$, b $2 \theta$ range from $30^{\circ}$ to $45^{\circ}$ 

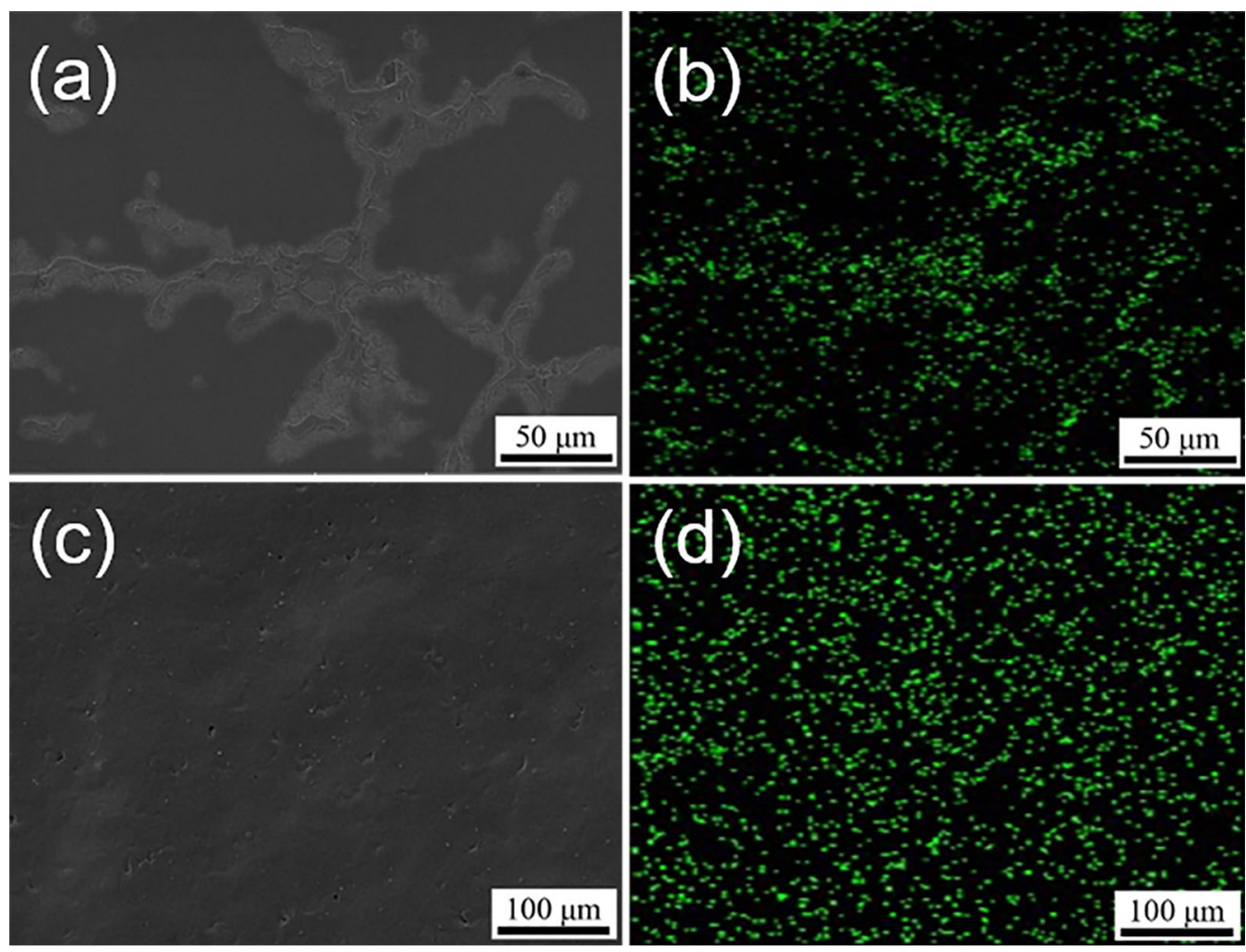

Fig. 4 EDS-layered map of AZ91 Mg alloy: a, b untreated, $\mathbf{c}, \mathbf{d}$ treated by HCPEB at the 5 pulses. b, $\mathbf{d}$ are the Al map of a, c, respectively

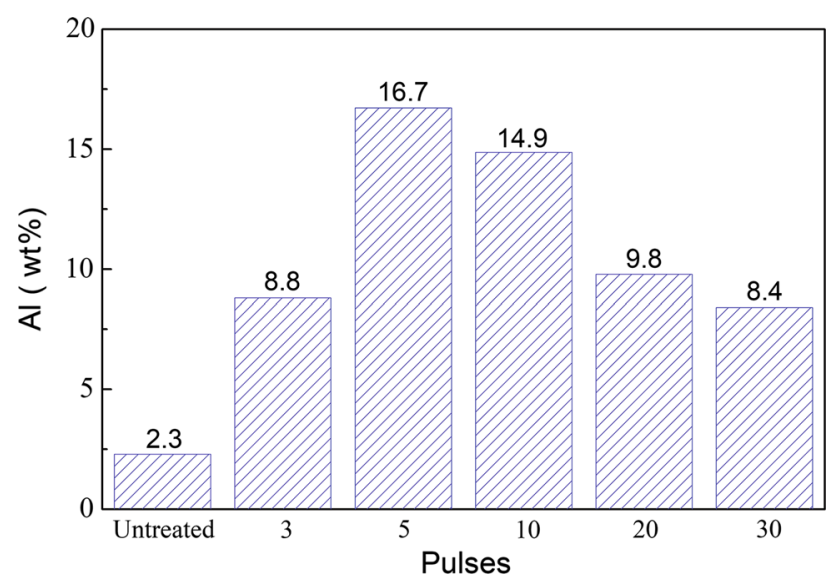

Fig. 5 Aluminum contents of $\alpha-\mathrm{Mg}$ in AZ91 Mg alloy treated by HCPEB

obvious after HCPEB treatment at 3 and 5 pulses as compared with that treated at 10 pulses. However, the obvious increase in $i_{\text {corr }}$ value appears as the pulses increase to 20 and 30, both of which are higher than that of untreated AZ91 alloy. That implies the HCPEB treatment will deteriorate the corrosion resistance of AZ91 alloy with the energy density $6 \mathrm{~J} / \mathrm{cm}^{2}$ by the number of pulses 20 and 30. Moreover, a passivation stage is found on the anodic curve of samples treated by HCPEB at 3, 5 and 10 pulses, which indicate the formation of protective surface film on the surface. The protective surface film has barrier effect during the corrosion process of materials. The stability of protective surface film could be estimated by the breakdown potential ( $E_{\mathrm{b}}$, as shown in Fig. 7) and the value of $E_{\mathrm{b}}-E_{\text {corr }}$. The relatively larger $E_{\mathrm{b}}-E_{\text {corr }}$ value and more positive $E_{\mathrm{b}}$ are obtained in alloy treated by HCPEB at 3 and 5 pulses as compared with alloy treated at 10 pulses, indicating that more stable and protective surface film formed on the surface of alloys treated by HCPEB at 3 and 5 pulses.

The corrosion rate $\left(C_{\mathrm{R}}\right)$ calculated by Eq. (1) is shown in Fig. 8 and Table 2. The $C_{\mathrm{R}}$ decreases significantly after HCPEB treatment by 3, 5 and 10 pulses. And the decrease in $C_{\mathrm{R}}$ in alloy treated at 5 pulses is more predominant. The calculated $C_{\mathrm{R}}$ value decreased by six times after treatment by HCPEB at 5 pulses compared with untreated AZ91 Mg alloy. While the $C_{\mathrm{R}}$ value increases significantly after being treated by 20 and 30 pulses, the calculated $C_{\mathrm{R}}$ value increases about by 2 and 4 times compared with untreated AZ91 Mg alloy.

EIS test is used to characterize the corrosion behavior in the corrosion process. The results of EIS test are shown in Fig. 9. The Nyquist plots of all samples present two capacitive loops: one capacitive loop in the high-frequency region and one capacitive loop in the medium-frequency region. The loop in the high-frequency region is the response of electrochemical reaction corresponding to the 

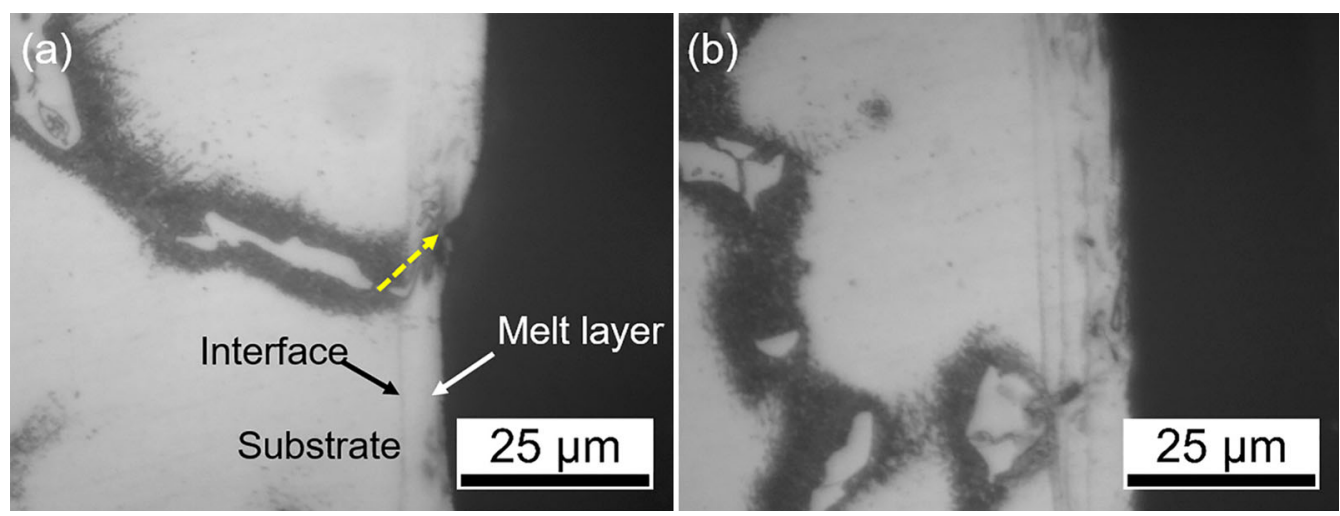

Fig. 6 OM micrographs of cross-sectional morphology irradiated for a 5 pulses, b 30 pulses

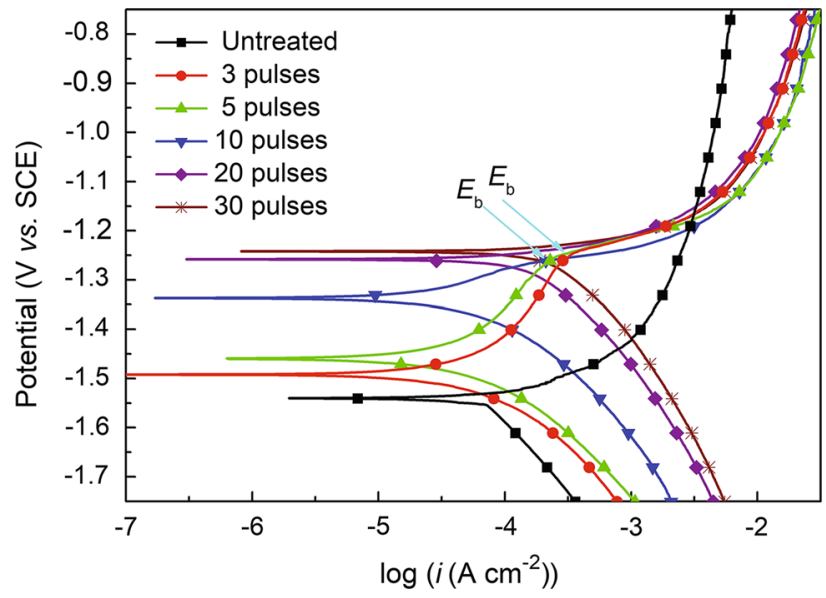

Fig. 7 Polarization curves of the samples

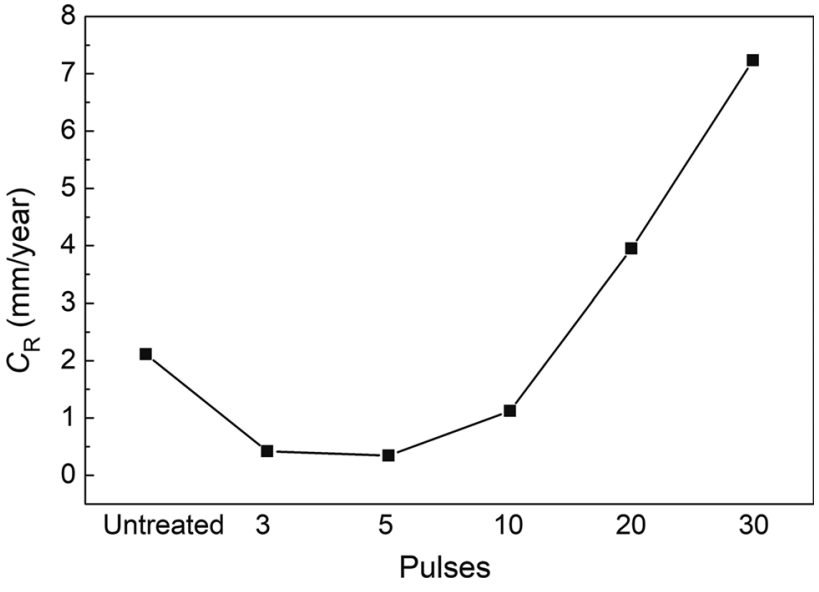

Fig. 8 Corrosion rates calculated by Eq. (1)

Table 2 Details obtained from polarization tests and $C_{\mathrm{R}}$ calculated by Eq. (1)

\begin{tabular}{lllllll}
\hline Pulses of HCPEB & $E_{\text {corr }}(\mathrm{V}$ vs. SCE $)$ & $i_{\text {corr }}\left(\mu \mathrm{A} / \mathrm{cm}^{2}\right)$ & $-b_{\mathrm{c}}(\mathrm{mV} / \mathrm{dec})$ & $E_{\mathrm{b}}(\mathrm{V}$ vs. SCE $)$ & $E_{\mathrm{b}}-E_{\text {corr }}(\mathrm{V})$ & $C_{\mathrm{R}}(\mathrm{mm} / \mathrm{year})$ \\
\hline Untreated & -1.540 & 72.7 & 260.33 & - & - & 2.12 \\
3 pulses & -1.492 & 18.4 & 105.61 & -1.240 & 0.252 & 0.42 \\
5 pulses & -1.459 & 15.1 & 101.29 & -1.248 & 0.211 & 0.35 \\
10 pulses & -1.337 & 49.1 & 105.32 & -1.262 & 0.075 & 1.12 \\
20 pulses & -1.258 & 172.9 & 171.68 & - & - & 4.00 \\
30 pulses & -1.242 & 316.6 & 207.83 & - & - & 7.23 \\
\hline
\end{tabular}

degradation of alloys. Another loop in the medium-frequency region is the response of barrier effect of film formed on the surface [10]. In Nyquist plots, the diameter of the semicircle is related to the corrosion resistance of the sample. The diameter of the semicircle increases as the pulses increase to 5 and then decreases with the further increasing pulses, implying that the alloy treated by 5 pulses shows the best anti-corrosive performance. Besides, the inductive loops appear in the low-frequency region of untreated AZ91 Mg alloy and the alloys treated by HCPEB at 20 and 30 pulses, which is an evidence that pitting corrosion happened on the surface.

The Bode plots of impedance versus frequency (Fig. 9b) show that the resistive value of impedance depicts same trend with diameter of capacitive loops in Nyquist plots: The resistive value increases as increasing pulses to 5 and then decreases as the further increase of pulses. The lower resistive value of alloy treated by 20 and 30 pulses indicates that the alloy shows inferior anti-corrosive behavior as compared with other alloys. All the samples in Fig. 9c 

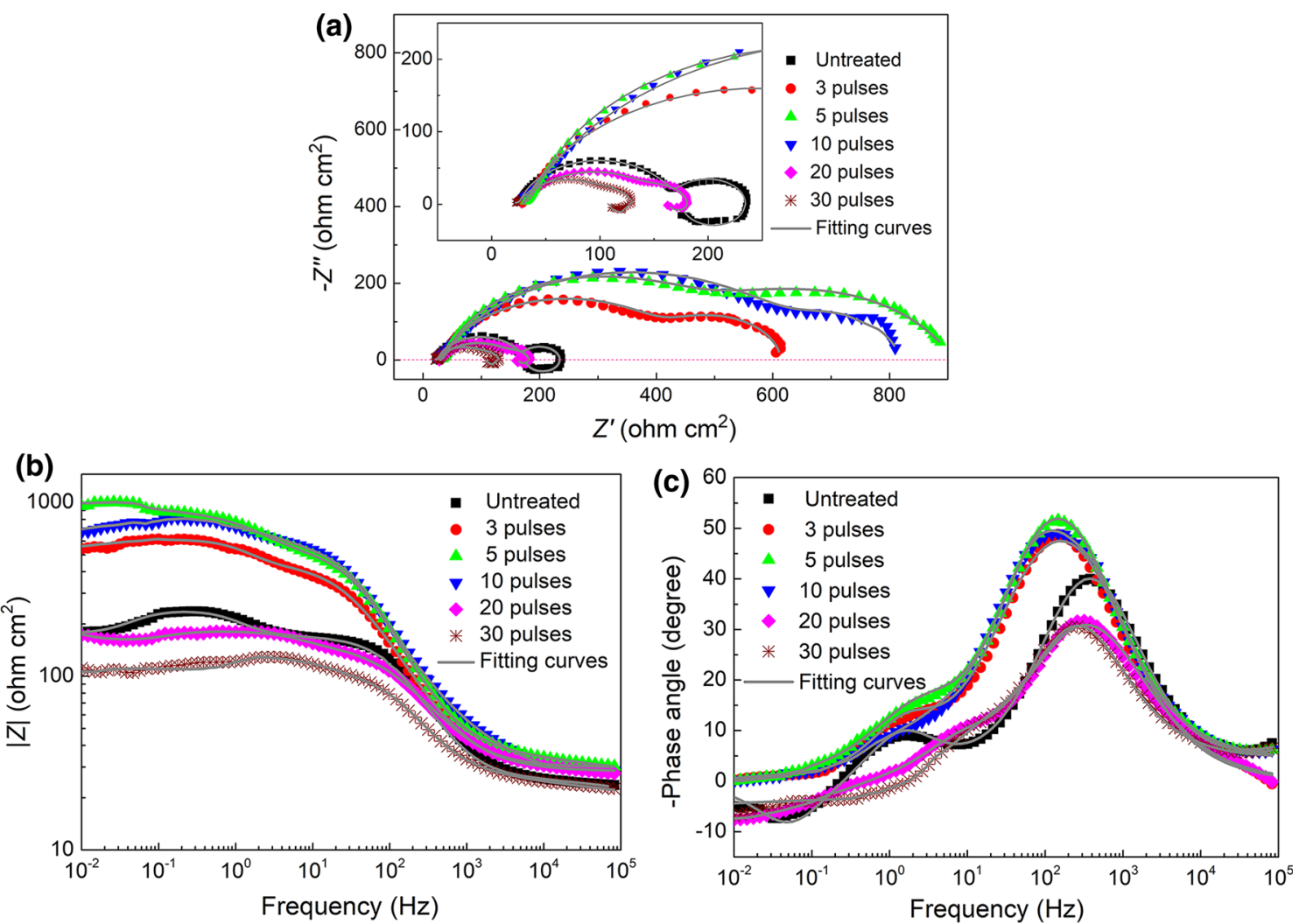

Fig. 9 Results of EIS test: a Nyquist plots, b IZI versus frequency of Bode plots, $\mathbf{c}$ phase angle versus frequency of Bode plots

present two time constants: one time constant in the highfrequency region and another time constant in the mediumfrequency region. The time constant in the high-frequency region is related to the appearance of double-layer capacitance $\left(C_{\mathrm{dl}}\right)$ at the interface of metal surface/corrosive medium and the corresponding charge transfer resistance $\left(R_{\mathrm{ct}}\right)$ in the corrosion process. Another time constant in the medium-frequency region is attributed to the barrier effect of film formed on the surface as a result of corrosion product.

In order to further analyze the corrosion mechanism of the alloys, the equivalent electrical circuits (EEC) (Fig. 10)

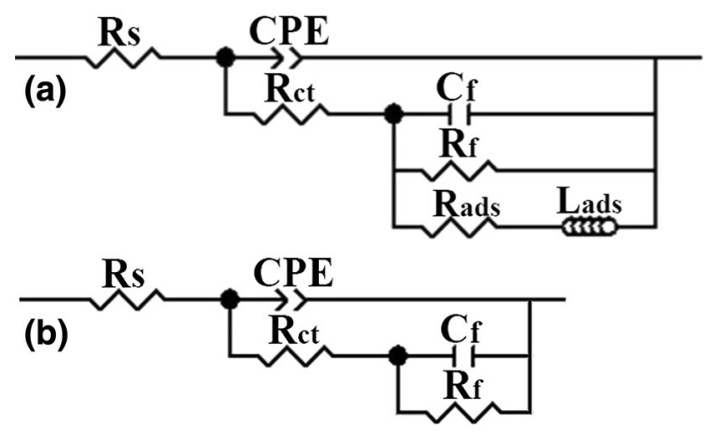

Fig. 10 EEC used in EIS data analysis of AZ91 Mg alloy: a untreated and treated by HCPEB at the pulses of 20 and 30, b treated by HCPEB at the pulses of 3,5 and 10 were used to model the EIS spectra and the fitting data of the EIS spectra are presented in Table 3. The parallel circuit of $C_{\mathrm{dl}}$ and $R_{\mathrm{ct}}$ describing the capacitance behavior of interface between metal surface and corrosive medium was replaced by a parallel circuit of constant phase element (CPE) and $R_{\mathrm{ct}}$. The conversion equation is given in Eq. (2) [5]:

$Y=Y_{0}(j \omega)^{n}$,

where $Y$ is the admittance of $C$, the $Y_{0}$ is the admittance of $\mathrm{CPE}$ and $n$ is the power index number. If $n$ equals $1, \mathrm{CPE}$ is identical to an ideal capacitor. The value of CPE is related to corrosion reaction area [11]. The higher the CPE value, the larger the corrosion area on the surface. The value of CPE decreases as pulses increase to 5 and then increases as the pulses further increase. After irradiated by 20 and 30 pulses, the CPE value is larger than AZ91 Mg alloy, meaning the larger corrosion reaction area on the surface of alloys treated by 20 and 30 pulses. The value of $R_{\mathrm{ct}}$ is related to the exchange current density $\left(i_{0}\right)$ as Eq. (3) reported by Udhayan and Bhatt [27]:

$i_{0}=\frac{R T}{n F R_{\mathrm{ct}}}$

where $n$ is the number of transferred charges and $F$ is Faraday constant. Apparently, the higher the $R_{\mathrm{ct}}$ value, the 
Table 3 Fitting results of EIS results of the samples in SBF solution

\begin{tabular}{llllllllll}
\hline $\begin{array}{l}\text { Pulses of } \\
\text { HCPEB }\end{array}$ & $\begin{array}{l}R_{\mathrm{s}}(\mathrm{ohm} \\
\left.\mathrm{cm}^{2}\right)\end{array}$ & $\begin{array}{l}\mathrm{CPE}\left(\times 10^{-6} \mathrm{O}^{-1}\right. \\
\left.\mathrm{cm}^{-2} \mathrm{~s}^{\mathrm{n}}\right)\end{array}$ & $n$ & $\begin{array}{l}R_{\mathrm{ct}}(\mathrm{ohm} \\
\left.\mathrm{cm}^{2}\right)\end{array}$ & $\begin{array}{l}C_{\mathrm{f}}(\mu \mathrm{F} / \\
\left.\mathrm{cm}^{2}\right)\end{array}$ & $\begin{array}{l}R_{\mathrm{f}}(\mathrm{ohm} \\
\left.\mathrm{cm}^{2}\right)\end{array}$ & $\begin{array}{l}L_{\mathrm{ads}}(\mathrm{H} \\
\left.\mathrm{cm}^{-2}\right)\end{array}$ & $\begin{array}{l}R_{\mathrm{ads}}(\mathrm{ohm} \\
\left.\mathrm{cm}^{2}\right)\end{array}$ & $\begin{array}{l}R_{\mathrm{p}}(\mathrm{ohm} \\
\left.\mathrm{cm}^{2}\right)\end{array}$ \\
\hline Untreated & 24.2 & 43.39 & 0.88 & 146.0 & 1952.0 & 62.8 & 183.1 & 35.2 & 208.8 \\
3 pulses & 30.3 & 33.02 & 0.81 & 427.4 & 758.8 & 159 & - & - & 586.4 \\
5 pulses & 36.0 & 27.78 & 0.81 & 592.2 & 483.2 & 262.3 & - & - & 854.5 \\
10 pulses & 20.6 & 40.74 & 0.82 & 474.7 & 904.6 & 133.6 & - & - & 608.3 \\
20 pulses & 28.4 & 52.90 & 0.76 & 129.7 & 914.1 & 14.8 & 30.41 & 20.3 & 144.5 \\
30 pulses & 25.6 & 133.1 & 0.83 & 93.8 & 925.3 & 12.9 & 7.39 & 15.3 \\
\hline
\end{tabular}

lower the exchange current density and thus the better the anti-corrosive behavior. It can be clearly found that the samples treated by 3,5 and 10 pulses show higher $R_{\mathrm{ct}}$ value, implying that the degradation of alloys can be suppressed by HCPEB treatment when the pulses are less than 10. After treated by 20 and 30 pulses, the $R_{\mathrm{ct}}$ value is lower than untreated AZ91 Mg alloy, which means that the exchange current density is higher in the alloys treated by 20 and 30 pulses than that in AZ91 Mg alloy. The better value of CPE and $R_{\text {ct }}$ of alloy treated by 5 pulses indicates its best corrosion resistance.

The film formed on the surface as corrosion product can be detected by the parallel $C_{\mathrm{f}}$ and $R_{\mathrm{f}}$ which describe the barrier effect of the film. The low $C_{\mathrm{f}}$ values of alloys treated by 3 and 5 pulses imply that a relatively thick and compact protective film forms on the metal surface [27]. Similar to the polarization results, the better barrier effect of the film is obtained in the samples treated by 3 and 5 pulses. $R_{\text {ads }}$ and $L_{\text {ads }}$ in the EEC can be ascribed to the release of the oxidation products such as $\mathrm{Mg}^{2+}$ or $\mathrm{Mg}(\mathrm{OH})_{2}$. In present work, the polarization resistance $\left(R_{\mathrm{p}}\right)$ was calculated by the following equation:

$R_{\mathrm{P}}=R_{\mathrm{ct}}+R_{\mathrm{f}}$.

As listed in Table 2, the best corrosion resistance is obtained in alloy when the pusle is 5 due to its better polarization resistance in EIS tests.

\section{Discussion}

It was reported that the $\mathrm{Mg}_{17} \mathrm{Al}_{12}$ phase has barrier effect during the corrosion process when the $\mathrm{Mg}_{17} \mathrm{Al}_{12}$ phase distributes continuously. However, the agglomerated $\mathrm{Mg}_{17} \mathrm{Al}_{12}$ phase will accelerate corrosion due to microgalvanic corrosion between $\mathrm{Mg}_{17} \mathrm{Al}_{12}$ phase and $\alpha-\mathrm{Mg}$ in aqueous solutions [24]. The $\alpha-\mathrm{Mg}$ dissolves as anodes in such micro-cells. The corrosion process can be expressed by these following equations [12]:
$\mathrm{Mg} \rightarrow \mathrm{Mg}^{2+}+2 \mathrm{e}^{-} \quad$ (anodic reaction)

$2 \mathrm{H}_{2} \mathrm{O}+2 \mathrm{e}^{-} \rightarrow 2 \mathrm{OH}^{-}+\mathrm{H}_{2} \quad$ (cathodic reaction)

$\mathrm{Mg}^{2+}+2 \mathrm{OH}^{-} \rightarrow \mathrm{Mg}(\mathrm{OH})_{2} \quad$ (product formation)

$\mathrm{Mg}+2 \mathrm{H}_{2} \mathrm{O} \rightarrow \mathrm{Mg}(\mathrm{OH})_{2}+\mathrm{H}_{2} \quad$ (over reaction).

The $\mathrm{Mg}_{17} \mathrm{Al}_{12}$ phase distributes continuously, and some isolated $\mathrm{Mg}_{17} \mathrm{Al}_{12}$ phase can also be found on the surface of AZ91 Mg alloy in the present research (Figs. 2a, 4a). After the $\alpha-\mathrm{Mg}$ around isolated $\mathrm{Mg}_{17} \mathrm{Al}_{12}$ is corroded completely, the $\mathrm{Mg}_{17} \mathrm{Al}_{12}$ can fall off and the corrosion pits are formed subsequently. This could be confirmed by the appearance of inductive phenomenon in Fig. 9. After being treated by $\mathrm{HCPEB}$ irradiation, the continuous $\mathrm{Mg}_{17} \mathrm{Al}_{12}$ phase disappears and more $\mathrm{Mg}_{17} \mathrm{Al}_{12}$ particles precipitate, and thus, the corrosion rate is supposed to increase. However, the corrosion rate decreased after HCPEB treatment by 3, 5 and 10 pulses. So it can be conducted that the $\mathrm{Mg}_{17} \mathrm{Al}_{12}$ is not the main factor influencing the corrosion behavior of AZ91 Mg alloy.

The decrease in corrosion rate of AZ91 Mg alloy after HCPEB treatment by 3, 5 and 10 pulses may be caused by the solid solution of Al element [28]. Makar reported that the rapidly solidified $\mathrm{Al}$ element can improve the corrosion resistance significantly. In other words, the corrosion resistance improves as the increase of solidified $\mathrm{Al}$ content in $\mathrm{Mg}$ alloy. The $\mathrm{Mg}$ alloy containing more solidified $\mathrm{Al}$ element present strong tendency to form a stable protective surface film in electrolyte which is in accordance with the polarization tests and EIS tests in the present work. The AZ91 Mg alloy treated by 5 pulses shows the highest solidified Al contents. As a result, it exhibits the best anticorrosive performance. Although the alloys treated by 20 and 30 pulses contain more solidified Al content than untreated AZ91 Mg alloy, they show inferior corrosion resistance. This is caused by the surface micro-cracks and pits. As the pulses increase to 20 and 30, more microcracks and pits are formed, as shown in Fig. 2d. Such cracks provide passageways where corrosive medium can 
get into inside of material. As a result, the material can be further corroded and the surface film formed on the surface previously can be broken.

\section{Conclusions}

(1) After irradiation by $\mathrm{HCPEB}$, the net-like $\mathrm{Mg}_{17} \mathrm{Al}_{12}$ phase disappeared. Crater-like and groove-like structures as well as micro-cracks are formed on the surface. The craters were caused by the eruption of melt $\mathrm{Mg}_{17} \mathrm{Al}_{12}$, and the micro-cracks resulted from thermal stress produced in surface layer during the rapid solidification and quenching processes of HCPEB treatment.

(2) The density of craters depended on the pulses, the high density of which was obtained when the pulse was 5. Besides that, the supersaturated Al element was also found on the surface of the HCPEB-treated AZ91 Mg alloy, and the largest $\mathrm{Al}$ content was obtained when the pulses are 5 .

(3) The AZ91 Mg alloy after HCPEB treatment by 3, 5 and 10 pulses showed better corrosion resistance than that without HCPEB treatment, which is mainly caused by the supersaturated $\mathrm{Al}$ element and the less surface micro-cracks. On the contrary, the HCPEBtreated AZ91 Mg alloy exhibited inferior anti-corrosive behavior once the pulse increased to 20 and 30 owing to the large amounts of micro-cracks on the surface.

Acknowledgements The authors gratefully acknowledge the finacial support from the National Natural Science Foundation of China (Nos. 51771128 and 51771129), the Projects of International Cooperation in Shanxi (No. 201703D421039) and the Natural Science Foundation of Shanxi (No. 201601D011034). The authors thank Dr. F.J. Xu and Dr. G.Z. Tang for experimental assistance and useful discussions.

\section{References}

[1] P. Ji, R.Y. Long, L.C. Hou, R.W. Wu, J.H. Zhang, M.L. Zhang, Surf. Coat. Technol. 350, 428 (2018)
[2] R. Wu, Y. Yan, G. Wang, L.E. Murr, W. Han, Z. Zhang, M. Zhang, Int. Mater. Rev. 60, 65 (2015)

[3] T.T. Yin, R.Z. Wu, Z. Leng, G. Du, X. Guo, M. Zhang, J. Zhang, Surf. Coat. Technol. 225, 119 (2013)

[4] N. Sezer, Z. Evis, S.M. Kayhan, A. Tahmasebifar, M. Koç, J. Magn. Alloys 6, 23 (2018)

[5] P. Wu, Z. Zhang, F. Xu, K. Deng, K. Nie, R. Gao, Appl. Surf. Sci. 426, 418 (2017)

[6] J.W. Seong, W.J. Kim, Acta Biomater. 11, 531 (2015)

[7] R.K. Gupta, K. Mensah-Darkwa, D. Kumar, J. Mater. Sci. Technol. 30, 47 (2014)

[8] Y. Zhu, G. Wu, Y.H. Zhang, Q. Zhao, Appl. Surf. Sci. 257, 6129 (2011)

[9] X.J. Wang, D.K. Xu, R.Z. Wu, X.B. Chen, Q.M. Peng, L. Jin, Y.C. Xin, Z.Q. Zhang, Y. Liu, X.H. Chen, G. Chen, K.K. Deng, H.Y. Wang, J. Mater. Sci. Technol. 34, 245 (2018)

[10] P. Wu, F. Xu, K. Deng, F. Han, Z. Zhang, R. Gao, Corros. Sci. 127, 280 (2017)

[11] J. Li, Q. Jiang, H. Sun, Y. Li, Corro. Sci. 111, 288 (2016)

[12] L. Hu, Q. Meng, S. Chen, H. Wang, Appl. Surf. Sci. 259, 816 (2012)

[13] N.V. Phuong, K.H. Lee, D. Chang, S. Moon, Corros. Sci. 74, 314 (2013)

[14] L. Xu, E. Zhang, K. Yang, J. Mater. Sci. Mater. Med. 20, 859 (2009)

[15] R. Rojaee, M. Fathi, K. Raeissi, Mater. Sci. Eng. C 33, 3817 (2013)

[16] A. Apelfeld, B. Krit, V. Ludin, N. Morozova, B. Vladimirov, R.Z. Wu, Surf. Coat. Technol. 322, 127 (2017)

[17] J. Zou, T. Grosdidier, K. Zhang, C. Dong, Acta Mater. 54, 5409 (2006)

[18] K. Zhang, J. Ma, J. Zou, Y. Liu, J. Alloys Compd. 707, 178 (2017)

[19] Y.K. Gao, J. Alloys Compd. 572, 180 (2013)

[20] B. Gao, S. Hao, J. Zou, W. Wu, G. Tu, C. Dong, Surf. Coat. Technol. 201, 6297 (2007)

[21] S. Hao, M. Li, Nucl. Instrum. Methods Phys. Res. Sect. B 375, 1 (2016)

[22] M.C. Li, S.Z. Hao, H. Wen, R.F. Huang, Appl. Surf. Sci. 303, 350 (2014)

[23] A.B. Markov, V.P. Rotshtein, Nucl. Instrum. Methods Phys. Res. Sect. B 132, 79 (1997)

[24] G. Song, A. Atrens, M. Dargusch, Corros. Sci. 41, 249 (1998)

[25] J. Liao, M. Hotta, Y. Mori, Mater. Sci. Eng. A 544, 10 (2012)

[26] Z. Shi, A. Atrens, Corros. Sci. 53, 226 (2011)

[27] R. Udhayan, D.P. Bhatt, J. Power Sour. 63, 103 (1996)

[28] G.L. Makar, J. Kruger, J. Electrochem. Soc. 137, 414 (1990) 